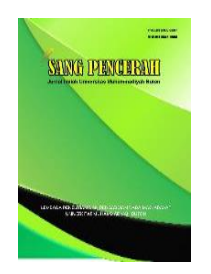

Volume 6 Issue 1, 2020

P-ISSN : 2528-360X, E-ISSN : 2621-6159

Website: https://www.jurnal-umbuton.ac.id/index.php/Pencerah

\title{
Citra Perempuan dalam Iklan Sabun Shinzui
}

\author{
${ }^{1}$ Risman Iye, ${ }^{1}$ Susiati, ${ }^{2}$ Karim
}

Email: rismaniye@gmail.com

\begin{abstract}
Advertising is a surefire tactic of producers in promoting an item or service so that interest and curiosity appear for consumers. This study aims to describe the characteristics of the image of women in Shinzui soap advertisements. This type of research uses qualitative methods with a semiotic approach. The data consists of two, namely primary data and secondary data. Data collection techniques in this research are observation and study of document contents. The data that has been obtained is then processed to look for the meaning contained in the data. The first thing to do is to write it in the form of a detailed description then reduce it (process it). The results showed that the three advertisements that became the research data have the same characteristics, namely in each scene the feminism traits have been shown, namely using a beautiful white dress, unraveling hair, a woman's posture that has purposional criteria and the image of women's figure is more highlighted in biological properties to attract consumers. Furthermore, the image of women in advertisements consists of two, namely having a biological or physical appeal and the attractiveness of gentle, graceful and graceful behaviors or characters.
\end{abstract}

Keywords: Advertisement; Shinzui Soap; Women

\begin{abstract}
Abstrak
Iklan merupakan suatu taktik jitu produsen dalam mempromosikan suatu barang atau jasa sehingga muncul ketertarikan dan rasa penasaran bagi para konsumen. Penelitian ini bertujuan untuk mendeskripsikan karakteristik citra perempuan dalam iklan sabun Shinzui. Jenis penelitian menggunakan metode kualitatif dengan pendekatan semiotik. Data terdiri atas dua, yakni data primer dan data sekunder. Teknik pengumpulan data dalam penelitian ini adalah observasi dan kajian isi dokumen. Data yang telah diperoleh selanjutnya diproses untuk dicari makna yang terkandung di dalam data. Pertama yang harus dilakukan adalah ditulis dalam bentuk uraian terperinci kemudian direduksi (diolah). Hasil penelitian menunjukkan bahwa ketiga iklan yang menjadi data penelitian memiliki karakteristik yang sama, yakni dalam setiap adegan telah ditunjukan sifat-sifat feminism, yakni menggunakan gaun putih yang indah, rambut terurai, postur tubuh wanita yang memiliki kriteria purposional serta citra figura perempuan lebih ditonjolkan pada sifat biologisnya untuk menarik minat konsumen. Selanjutnya, citra perempuan dalam iklan terdiriatas dua, yakni memiliki daya tarik biologis atau fisik dan daya tarik perilaku atau karakter lemah lembut, gemulai dan anggun.

Kata Kuci: Iklan; Sabun Shinzui; Perempuan
\end{abstract}

\section{PENDAHULUAN}

Perkembangan teknologi, secara otomatis akan sangat mempengaruhi aspek budaya dan kehidupan sosial suatu bangsa (Rahman, 2017). Pesatnya perkembangan ilmu pengetahuan dan teknologi dewasa ini sangat berpengaruh terhadap perkembangan media massa,

\footnotetext{
${ }^{1}$ Universitas Iqra Buru, Indonesia

${ }^{2}$ Institut Agama Islam Negeri Kendari, Indonesia
}

khususnya media elektronik bukan hanya kualitas informasinya tetapi media juga memiliki peran dan fungsi yang lebih luas, bahkan media sering disebut sebagai kekuatan penyeimbangan bagi kehidupan politik, ekonomi, pemerintahan, budaya, nilai dan norma kemasyarakatan. Salah satu media elektronik yang cukup pesat perkembangannya adalah televisi. Televisi 
muncul di barisan akhir dari pada media massa lain. Televisi sebagai media massa dengan kelebihan yang dimiliki, tidak lalu menjadi saingan dari media massa lainnya, bahkan bersama media cetak dan radio merupakan Tritunggal media mssa yang mempunyai pengaruh dan dengan sendirinya akan membentuk kekuatan besar, sebagai tantangan bagi pengelolanya, karena harus manjawab tantangan tersebut.

Televisi hadir sebagai kekuatan bisnis di Indonesia hal itu karena media televisi mau tidak mau harus hidup dari langganan dan iklan yang kemudian persaingan tajam pun terjadi. Bisnis dan idialisme pers bagaikan Vicious Circle (lingkaran tak berujung).

Bisnis Televisi mulai marak sekitar 10 tahun terakhir sejak televisi swasta mulai bermunculan dan diizinkan beroperasi. Mulailah terjadi persaingan antar media televisi. Bisnis televisi disini kaitannya erat dengan iklan, rating adalah acuan dari jumlah penonton televisi disebuah stasiun pada acara, jam, hari tertentu yang datanya di peroleh berdasarkan survey khalayak yang komprehensif oleh sebuah biro penelitian yang independent dan mempunyai kredibilitas tinggi.

Televisi berkembang begitu cepat sejalan dengan perkembangan teknologi sekarang yang mana telah menjadi sesuatu yang trend saat ini. Perannya sangat besar dalam membentuk pola dan pendapat umum, termasuk pendapat umum untuk menyenangi suatu produkproduk tertentu, demikian pula perannya amat besar dalam membentuk perilaku dan pola berfikir. Benar-benar suatu fenomena besar pada abad ini dan yang tidak pernah di bayangkan oleh penemu televisi sekitar 50 tahun yang lalu. Perkembangan demikian cepat dan meluas sehingga kerap kali tidak dapat memahami sepenuhnya arah dan perkembangan serta yang akan terjadi dimasa yang akan datang.

Dalam perjalanan perkembangan bisnis pertelevisian tak bisa lepas dari peran iklan. Iklan diperhitungkan menjadi faktor utama perubahan dan perkembangan sebaah televisi. Iklan dan televisi diibaratkan ikan dan air disatu pihak tidak bisa dinafikkan bahkan saling membutuhkan. Meskipun tugas utama iklan televisi sebanarnya adalah menjual barang atau jasa karena kemampuan media televisi dapat mendemonstrasikan produk agar khalayak memahami konsep produk.

Periklanan memainkan peranan amat penting dalam pembagian informasi sehingga dapat membantu konsumen untuk membuat keputusan pembelian terhadap produk. Iklan sebagai media komunikasi yang efektif diperlukan untuk mempromosikan suatu produk baik yang sifatnya baru maupun sudah lama.

Sebuah iklan yang baik haruslah persuasif agar dapat menarik minat konsumen. Selanjutnya, suatu iklan juga harus memperlihatkan kelebihan, manfaat, pesan secara jelas yang akan didapat oleh para konsumen terhadap barang atau jasa tersebut. Etika dalam periklanan harus diutamakan. Periklanan yang baik akan memberikan konstribusi terhadap nilai suatu perusahaan dan gambaran kemampuan manajemen pemasaran dalam meningkatkan petumbuhan perusahaan baik dalam jangka waktu pendek maupun jangka panjang.

Menurut Rancangan Undangundang (RUU) penyiaran penayangan iklan harus bersifat kearifan lokal atau berlatar belakang budaya Indonesia. Persoalan ini sebenarnya menyangkut etika penayangan iklan. Harus diketahui bahwa masih banyak iklan pertelevisian yang menampakkan sesuatu kejadian dimana bintang iklan setelah memekai produk yang diiklankan langsung sembuh atau kulitnya yang hitam langsung seketika putih. Contohnya seorang wanita cantik mengeluhkan kulitnya yang kasar, lalu setelah ia 
menggunakan bedak atau body lotion tertentu, kulitnya seketika halus dan beberapa pria tampn melirik atau mendekatinya. Hidup sebenarnya tak semudah itu.

Berbicara tentang iklan banyak sekali produk atau jasa yang diiklankan seperti iklan produk kecantikan, makanan, detergen, obat-obatan dan sebagainya dibintangi oleh model wanita. Dapat diperkirakan hampir 90\% periklanan memanfaatkan wanita sebagai model iklannya. Wanita sering dideskripsikan sebagai manusia yang mempunyai kepedulian tinggi terhadap rumah tangga, yang digambarkan secara fisik baik dari baju, bentuk tubuh, dan mimik muka. Namun, tanpa disadari iklan ini malah menyudutkan kaum lakilaki yang seolah-olah laki-laki tidak peduli terhadap rumah tangga padahal keperdulian kaum laki-laki adalah pekerjaan, bisnis, urusan publik, olah raga atau mobil. Ironisnya banyak diantara kaum wanita sendiri tidak menyadari bias iklan tersebut bahkan menganggapnya sebagai suatu hal yang wajar dan tidak perlu dipersoalkan.

Tomagola (1998) memberikan gambaran umum mengenai wajah wanita di media massa, khusunya dalam iklan yang memberikan pengertian mengenai nilai yang berkaitan dengan peran gender yang ada di belakang gambaran tersebut. Gambaran ini diambail dan disarikan dari Disertasi untuk meraih gelar doktornya, yang menganalisis 'isi' dari empat majalah terkenal di Jakarta. Keempat majalah wanita itu adalah: femina, kartini, sarinah, dan pratiwi yang diterbitkan antara tahun 1986 s.d 1990. Adapun isi dari keempat majalah tersebut adalah artikel dan iklan. Penelitian itu menghasilkan lima kategori citra perempuan yang digambarkan oleh iklan dari keempat majalah wanita tersebut, yakni pertama, Citra Pigura, dari sini iklan menggambarkan dan menekankan bahwa betapa pentingnya para wanita kelas menengah ke atas untuk selalu tampil 'memikat'. Seorang wanita perlu mempertegas kewanitaanya yang telah terberi secara biologis maupun yang telah terpatri secara budaya seperti mempunyai rambut yang panjang dan hitam, alis mata yang indah, kulit yang halus.

Iklan-iklan lain yang masih iklan produk inipun juga selalu menggunakan model wanita, padahal dalam kenyataan produk ini adalah produk yang tidak hanya dipakai oleh kaum wanita saja. Bukan hanya iklan ini kebanyakan iklan dari produk sabun mandi didominasi oleh model wanita, meskipun ada satu dua yang menggunakan model pria.

Mengingat bahwa produk kecantikan diperuntukkan bagi kaum wanita. Suatu televisi melalui iklannya dapat dapat memperjelas persepsi masyarakat, sikap, kepercayaan, dan norma kaum wanita yang sudah ada. Kepercayaan yang muncul itu dapat berbentuk suatu persepsi bahwa iklan tersebut dapat menjadikan fisik mereka menjadi indah sehingga tidak heran jika pihak produksi dan petelevisian mendatangkan artis-artis cantik untuk menjadi bintang iklan mereka sehingga hal ini mendatangkan atau memancing para khalayak/masyarakat untuk memakai sabun yang diiklankan.

Williams (1993:320) menyatakan bahwa iklan seperti dunia khayal yang dapat mengubah komoditas ke dalam situasi gemerlap yang memikat dan mempesona, sebuah sistem yang yang keluar dari imajinasi dan muncul kedalam dunia nyata melalui media. Peran pertelevisian sangat penting dalam memberikan kesan indah pada suatu produk yang diiklankan. Iklan juga memberikan suatu wawasan kepada pemirsa dan khyalan yang tinggi kepada khalayak ramai. Iklan juga memakai prinsip-prinsip komunikasi massa sebagai media konstruksi dan berusaha selalu memberikan nilai tinggi pada suatu barang yang diiklankan.

Darwis dan Taufik (2018:45) mengatakan bahwa iklan televisi 
merupakan salah satu dari iklan lini atas (above-the-line). Umumnya, iklan terdiri atas iklan politik, iklan layanan masyrakat, Promo Ad, iklan spot, dan iklan sponsorship. Masyarakat sudah menjadikan iklan suatu hiburan dan kebutuhan mereka karena bagi masyarakat iklan dapat menyediakan gambaran tentang realitas dan sekaligus mendifinisikan keinginan dan kemauan dari setiap individu. Iklan pula mendeskripsikan tentang selera dan gaya. Perlu digaris bawahi bahwa iklan bukan hanya sebagai sarana melainkan sebagai sebuah tujuan yang diinginkan dan tidak bisa untuk dipertanyakan.

\section{Menurut During}

(1998:46)

mengatakan bahwa iklan tidak lagi hidup dalam abad ke-18, telah tumbuh dan berkembang menjadi sebuah realitas yang dapat membangkitkan sebuah tatanan sosial baru. Adapun wujud atau bentuk iklan terdiri atas tujuh kategori utama, yakni (1) iklan antarbisnis, (2) iklan konsumen, (3) iklan rekruitmen, (4) iklan keuangan, (5) iklan langsung, (6) iklan eceran, dan (7) iklan perdagangan (Jefkins, 1996:39).

Perempuan hampir tidak pernah terlupakan dalam penulisan puisi, novel, dan karya-karya tulis lain namun boleh dikatakan terlupakan dalam setiap penulisan sejarah (Iye, 2018). Implikasinya adalah perempuan sering dilihat sebagai obyek yang pasif dari pada subyek yang aktif. Namun kemajuan jaman menuntun kaum wanita untuk memperbaiki citranya. Kaum perempuan kini merambah (Fifiana, 2010).

Dengan cepat dan sukses dalam berbagai bidang kehidupan. Lembaran sejarah kini dan masa depan menggambarkan kian besarnya dan cerahnya peran dan posisi perempuan didalamnya disamping serentetan masalah yang harus di pecahkan seputar masalah citra perempuan dalam media.

Disela permasalahan seperti itu dan yang selama ini harus dihadapi, kini citra perempuan dalam berbagai media massa perlahan mulai berubah, hal inilah yang patut disyukuri oleh kaum perempuan.

Adapun tujuan dalam penelitian ini adalah mendeskripsikan citra perempuan dalam iklan Sabun Shunzuii kajian semiotik.

\section{METODE}

Jenis penelitian dalam penelitian ini adalah metode deskriptif kualitatif dengan menggunakan pendekatan semiotik. Pendekatan semiotik adalah pendekatan yang mengungkapkan gejala holistik kontekstual atau secara menyeluruh dan sesuai konteks dengan mengumpulkan data latar alami sebagai sumber langsung dan peneliti sebagai instrument. Melalui telaah bahasa, gambar, warna, musik, ideologi kewanitaan dan perilaku, model yang bertindak sebagai tanda dalam iklan Shinzui di televisi.

Jenis data pada penelitian terdiri atas dua yakni.

a. Data Primer

Data primer diperoleh dari hasil pengamatan obyek penelitian secara langsung sebagai temuan yang menjadi bahan kajian dalam penelitian ini termasuk dokumentasi dari iklan Shinzui versi Festival Film Internasional yang ada di televisi.

b. Data Sekunder

Data sekunder diperoleh diperoleh peneliti dari sumber lain (literatur atau kepustakaan) dan penjelasanpenjelasan teoretik yang mampu mendukung penelitian ini.

Sumber data dalam penelitian ini adalah media televisi dan youtube yang memuat Iklan Sabun Shinzui versi Festival Film Internasional.

Adapun teknik pengumpulan data yang digunakan dalam penelitian ini adalah dengan cara:

a. Observasi, yaitu proses di mana peneliti secara langsung mengamati setiap komponen kejadian atau 
peristiwa yang terjadi dalam iklan Sabun Suinzui yang ada di TV dan Youtube, terutama yang mengarah pada citra perempuan.

b. Kajian Isi Dokumen

Dalam kajian isi dokumen mendeskripsikan suatu proses melihat dan memeriksa kembali data-data dari dokumentasi yang ada, baik dari dokumentasi iklan ataupun data-data lain yang telah terkumpul.

\section{PEMBAHASAN}

\subsection{Sinopsis Iklan}

Objek dalam penelitian menggunakan tiga iklan sabun Shinzui yakni:

\section{a. Iklan Sabun Shinzui 1}

Dalam iklan ini seorang perempuan dengan tampilan anggun. Dalam adeganya seoramg perempuan menyingkap kain putih serta memnyentilkan jarinya mengahadap ke atas dalam untaian jatuhnya kembang bunga sakura. Dalam iklan ini juga terdapat instrument musik jepang dengan narasinya "shinzui Asayaka. Begitu harum meneyenagkan. mengandung herba Matsu Oil untuk mencerahkan kulitmu. sabun shuinzui melembutkan dan membuatmu seputih wanita jepang. karena ptih itu shinzui"

\section{b. Iklan Sabun Shinzui 2}

Pada iklan kedua seperti halnya juga pada pemeran iklan pertama yakni diperankan oleh perempuan namun dalam konteks situasi wanita tersebut berada di pinggir danau dengan berpose memegang tangan kirinya sambil melihat bahu. Pada iringan music antara iklan satu dan dua terdapat kesaamaan karena yang dgunakan adalah music jepang dengan dan dalam narasi pada iklan kedua tidak lagi menngunakan kata melembutkan melainkan melainkan memepsona.

\section{c. Iklan Sabun Shinzui 3}

Pada Iklan ketiga diperankan oleh wanita yang berambut pendek dengan pose di danau dengan memeakai baju putih. Dalam iklan ini juga wanita yang memerankanya juga terlihat mengusap sabun pada tubuhnya dengan iringan music jepang. "shinzui Asayaka. Begitu harum meneyenagkan. mengandung herba Matsu Oil untuk mencerahkan kulitmu. shinzui body schore mengangkat kotoran dan sel kulit mati dengan harum khas bunga jepang kulit halus dan cerah memebuatmu seperti wanita jepang"

\subsection{Citra Perempuan dalam Iklan Shuinzui}

\section{a. Memiliki Daya Tarik Biologis}

Citra perempuan dalam iklan 1 jika dikaitkan dengan teori feminisme maka dalam setiap adegan telah ditunjukkan sifat-sifat feminisme yakni, rambutnya yang terurai, kulit yang putih mulus, menggunakan gaun putih yang indah, postur tubuh purposional. Citra figura perempuan pada iklan Shinzui lebih ditonjolkan pada sifat biologisnya atau bentuk fisiknya. Hal ini bertujuan untuk menarik, memengaruhi, dan memunculkan hasrat minat konsumen. Dalam pemilihan model misalnya, yang berambut panjang, muka mulus dan putih, serta cantik dapat menambah rasa kepercayaan para konsumen terhadap iklan yang ditawarkan.

Dalam iklan Shinzui citra perempuan sangat berbeda atau bertolak belakang dengan citra di 
dalam Masyarakat sendiri. citra perempuan harus menjadi seorang perempuan yang legowo dalam artian seorang perempuan harus menurut dan terima, karena tugas utama seorang perempuan hanya menjadi sosok ibu rumah tangga saja, mengurus suami dan anak, dan seakan-akan perempuan tidak bisa mengeksplorkan apa yang dia inginkan. Jika dikaitkan dengan teori feminism, iklan Shinzui menunjukkan bahwa setiap scene-scene dalam iklan tersebut merupakan suatu gerakan kaum perempuan. Hal tersebut dibuktikan bahwa perempuan bebas mengeksplor dirinya, salah satunya menjadi model iklan.

\section{b. Daya tarik perilaku (lemah lembut, gemulai, anggun)}

Jika dikaitkan dengan teori feminisme, citra perempuan dalam iklan Shinzui menunjukkan sifat-sifat feminime, diantaranya sifat anggun, gemulai, anggun dan lemah lembut. Hal ini dilakukan agar menambah rasa kepercayaan konsumen terhadap iklan yang ditawarkan dan sebagai daya tarik tersendiri. Di dalam iklan Shinzui jika dikaitkan dengan teori feminisme menunjukkan bahwa setiap scene-scene gerakan kaum perempuan yang membuktikan bahwa perempuan bebas mengeksplor dirinya, salah satunya menjadi model iklan.

\section{KESIMPULAN}

Berdasarkan hasil penelitian dalam pembahasan sebelumnya, dapat disimpulkan beberapa hal yang menjadi temuan dalam penelitian ini terkait citra perempuan dalam iklan Sabun Shunzuii kajian semiotik. Ketiga iklan yang menjadi data dalam penelitian memiliki karakteristik yang sama, yakni dalam setiap adegan telah ditunjukan sifat-sifat feminisme, yakni menggunakan gaun putih yang indah, rambut terurai, postur tubuh wanita yang memiliki kriteria purposional serta citra figura perempuan lebih ditonjolkan pada sifat biologisnya untuk menarik minat konsumen sedangkan citra perempuan dalam iklan terdiri atas dua, yakni memiliki daya tarik biologis atau fisik, serta daya tarik perilaku atau karakter lemah lembut, gemulai, dan anggun.

\section{DAFTAR PUSTAKA}

Darwis, A \& Ismail, T. (2018). Citra Perempuan Dalam Iklan Sabun Media Elektronik (Kajian Feminisme). Makassar: Pendidikan Bahasa Indonesia, Pascasarjana Universitas Negeri Makassar.

During. (1998). The Cultural Studies Reader.. London: Routledge.

Fifiana, Friscillia. 2010. Representasi Citra Perempuan dalam Iklan Clear Soft and Shiny Versi "Sandra Dewi". Fakultas Ilmu Sosial dan Ilmu Politik Program Studi Ilmu Komunikasi. Surabaya: Universitas Pembangunan Nasional “Veteran" Jawa Timur.

Jefkins, Frank. 1996. Advertising (Periklanan). Jakarta: Airlangga.

Iye, R., \& Susiati, S. 2018. "Nilai Edukatif Dalam Novel Sebait Cinta Di Bawah Langit Kairo Karya Mahmud Jauhari Ali (Educative Values in Sebait Cinta di Bawah Langit Kairo Karya Mahmud Jauhari Ali". Sirok Bastra, 6 (2), 185-191.

Rahman, F. (2017). Cyber Literature: A Reader Writer Interactivity. International Journal of Social Sciences \& Educational Studies, Vol. 7, pp. 156-164. https://doi.org/10.23918/ijsses. v3i4p156

Tomagola, T, A. (1998). Citra Wanita dalam Iklan, dalam Majalah Wanita 
Indonesia; Suatu Tinjauan Sosiologis Media", dalam Ibrahim, Idi Subandy dan Suranto, Hanif, (ed)., Wanita dan Media: Konstruksi Ideologi Gender dalam Ruang Publik Orde Baru. Bandung: Rosda.

Williams, Raymond. (1993). Advertising: The Magic Sistem, dalam Simon During, The Cultural Studies Reader. London: Routledge. 